\title{
A Working Integrated Model for the Diffusion of Construction Innovation
}

\author{
${ }^{1}$ Ahmad Rahman Songip, ${ }^{1}$ B.H. Lau, \\ ${ }^{2}$ Kamaruzaman Jusoff and ${ }^{3}$ Hayati Nor Ramli \\ ${ }^{1}$ Malaysia-Japan International Institute of Technology, \\ Universiti Teknologi Malaysia Kuala Lumpur, Jalan Semarak, 54100 Kuala Lumpur, Malaysia \\ ${ }^{2}$ Perdana School of Science, Technology and Innovation Policy, \\ Universiti Teknologi Malaysia Kuala Lumpur, Jalan Semarak, 54100 Kuala Lumpur, Malaysia \\ ${ }^{3}$ School of Architecture, Building and Design, Taylor's University, \\ Lakeside Campus, No. 1, Jalan Taylor's 47500 Subang Jaya, Malaysia
}

Received 2012-12-30; Revised 2013-02-11; Accepted 2013-03-30

\begin{abstract}
Construction industry is said to be low in innovation and adoption of innovations is necessary to gain competitive advantage in a liberalized and globalized marketplace. This study investigated the factors that influenced the diffusion of construction innovations and developed an integrated framework to improve the diffusion process. A conceptual model was developed to guide the study and the modification of a questionnaire used in previous study of similar nature. The dependent variable was extent of diffusion and 10 independent factors were identified and categorized into industry characteristics, innovation attributes, adopter innovative characteristics and environmental interventions. A questionnaire survey was conducted on large and established construction firms in Malaysia. A randomized sample of 525 firms was selected and the primary data were collected by selfadministered postal survey. The response rate was $28 \%$. Data analysis was carried out using Statistical Package for Social Science (SPSS) Version 12. Among the factors, innovative culture was found to be most significant and influenced diffusion positively. In contrast with most of the previous studies conducted in developed countries, this study was conducted in Malaysia. It is likely to benefit the construction industry of developing countries of similar settings. The integrated framework of innovation diffusion will benefit homegrown innovation developers in more successful diffusion of their future construction innovations.
\end{abstract}

Keywords: Integrated Model, Construction Innovation, Innovation Diffusion, Construction Industry, Innovation Developers, Adopter of Innovation, Success of Innovation

\section{INTRODUCTION}

Organizations are embracing innovation in all aspects in facing competition and challenges brought about by globalization. The stormy and competitive commerce atmosphere of a globalized economy necessitates companies to constantly innovate so as to increase the competitive advantage to sustain development. Holt and Edwards (2012) affirms that innovation is crucial as assurance to business sustainability. A study by Hussain and Ilyas (2011) further clarify that dedication to innovation is crucial for a remarkable accomplishment in business besides maintains the competitive advantage. This is even truer nowadays with global commerce liberalization that brought reputable overseas organizations to compete with the homegrown businesses. This infers the customary business approaches building on low-priced

Corresponding Author: Ahmad Rahman Songip, Malaysia-Japan International Institute of Technology, Universiti Teknologi Malaysia Kuala Lumpur, Jalan Semarak, 54100 Kuala Lumpur, Malaysia 
as insufficient as there is the need to innovate by companies in order to increase proficiency, value and output. Ling (2003) states that innovation is now the fourth competitive dimension in addition to the conventional three dimensions of cost, quality and time.

In order to realize the economic advantages, innovation must be diffused and implemented by the society. Hall and Khan (2002) clarify that it is the diffusion that "ultimately determines the pace of economic growth and the rate of change in productivity" and not the invention or innovation. They also advised that innovation will contributes nothing until users fully adopt the new technology. The effectiveness of diffusion will encounter "adoption, implementation and institutionalization" (Murray, 2009). As a result, the diffusion of innovation has triggered the attention of business investors, as socio-economic gains will only achievable through a successful diffusion practice. This is clarified by Materna (1981) that more than two-thirds of unsuccessful technology transfer is caused by inefficient diffusion and it require up to $80 \%$ of the overall cost to develop an invention to profitable trade. Obviously, the diffusion phase in an innovationdevelopment process is important and it is necessary to have a better understanding of the diffusion process to ensure a better success rate of an innovation.

The construction industry has often been viewed as underachiever in innovation and the main reason is of its slow acquiring of new technologies (CIDB, 2005a), particularly in the acceptance of local innovations. Research of productivity growth indicator specifically associated to construction innovation frequently perceives that construction industry has low innovation achievement (Brochner, 2011). With the exception of mega projects, which often involve foreign participants, local construction firms still preferred time-proven traditional construction methods. This can be attributed to the perception that innovations are risky and expensive, at least in the mind of small construction firms. In addition, it is reported that private firms seldom conduct research and development on construction innovations (CIDB, 2005b).

There is an already substantial research achievement on construction innovation (Larsen, 2005) and only recently the study of diffusion practice becomes sensations. There are over 5,200 publishing on diffusion studies (Rogers et al., 2005) However, majority inclines to concentrate on the technicality of a particular technology and not many elaborate the diffusion of technology in a community (Dieperinka et al., 2004). Rogers et al. (2005) also confirms that innovation diffusion researches are mostly of technical-based, some are policies or others are of community education innovations. One good example related to construction industry is the study of the diffusion model of technology innovation in Computer Aided Design (CAD) by Kale and Arditi (2010).

The irregularity in the innovation diffusion research results acquired in other disciplines has made it necessary to conduct separate studies for the construction industry with most of these studies are carried out in the United States of America and until recently only a handful are conducted in United Kingdom and Australia. These studies (Blackley and Shepard, 1996; Toole, 1998; Cavell et al., 2004; Larsen and Ballal, 2005; Manley et al., 2005; Panuwatwanich et al., 2009) are conducted in developed countries, which have industry settings different from developing countries, for example Malaysia. Their findings and recommendations may not be directly applicable.

Rogers (1995) says that diffusion process was a kind of social change, defined as the process by which alterations occurred in the structure and function of a social system. Study of innovation process by taking the diffusion approach, therefore, is able to yield insights with regard to the reluctance on the part of builders to change their mindset with regard to innovation. Apart from that, an innovation can only bring economic benefits unless and until it is diffused and adopted by substantial number of members of a social system. In this respect, exploring the factors that influence the diffusion process will lead to better understanding of the diffusion mechanism, which can then assist the local innovation developers in the promotion of their innovations.

Relating to the problem statement described above, the objective of this study is to investigate the diffusion of construction innovation and to identify and establish factors which influence the diffusion process in the construction industry. It is intended to gain better understanding of the diffusion-adoption process for more successful diffusion of future construction innovation. Using the settings in Malaysia, it is hoped that the study can benefit construction players in developing countries.

\subsection{Conceptual Model}

The authors have proposed the conceptual model for construction innovation (Songip et al., 2013), as shown in Fig. 1. This conceptual model was developed from Rogers's framework on rate of adoption (Rogers, 1995), Brown (1981) framework on adopter behavior and related research on construction innovations (Songip et al., 2013). There are five constructs in Rogers (1995) framework, namely perceived attributes of innovation, type of innovationdecision, communication channels, nature of the social system and extent of change agents' promotion efforts. 


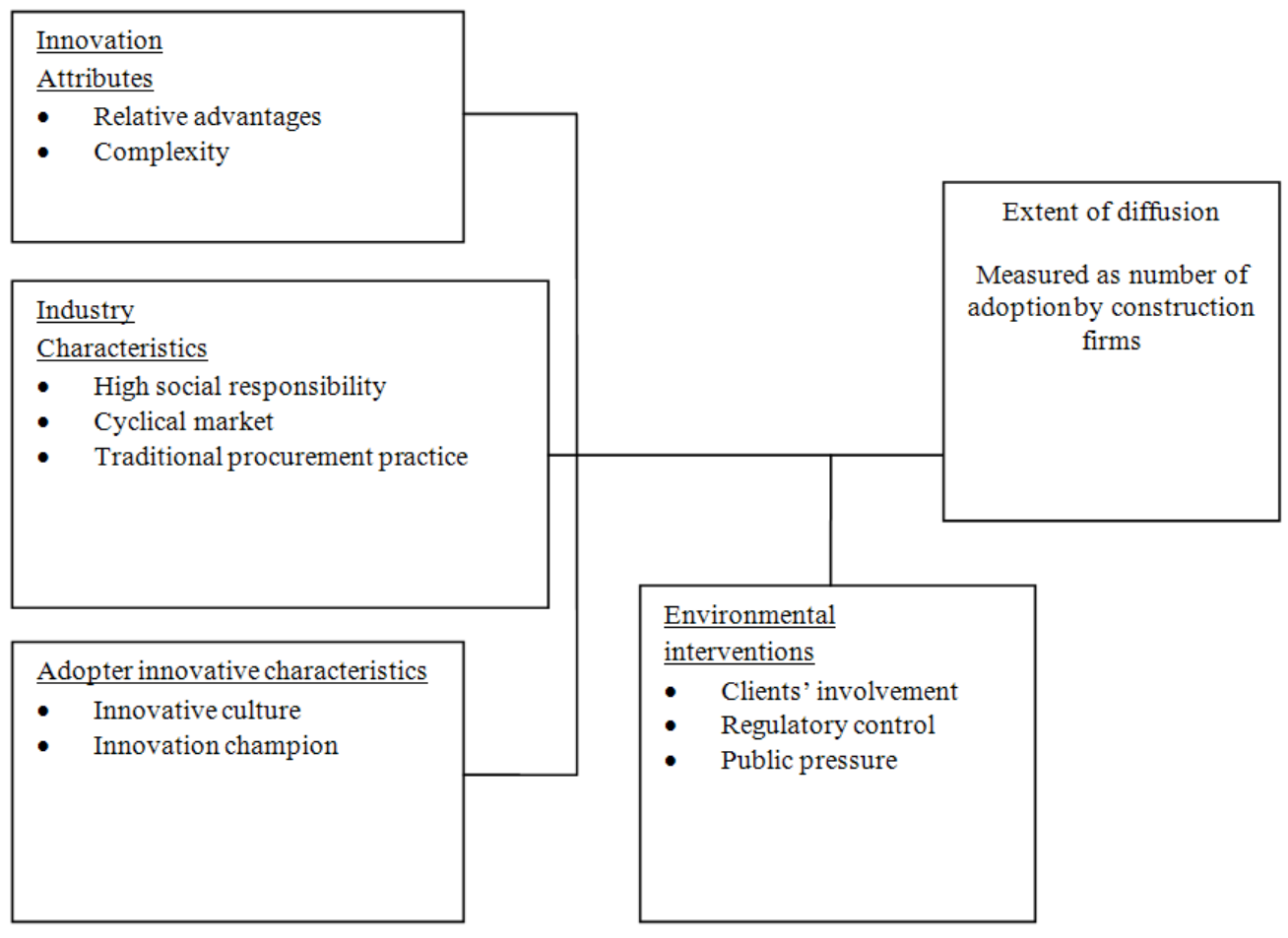

Fig. 1. The proposed conceptual model for construction innovation

Brown (1981) examines the adoption behaviour of adoption firms with four constructs in his framework namely characteristics of the innovation, industry characteristics, institutional effects and firm characteristics. This study investigated the extent of adoption as a measure on the degree of success of innovation and the focus is the supply side of innovation, i.e., the home-grown innovation developers. Brown (1981) framework emphasises more on the supply side, hence his proposed constructs were found to be more relevant.

The proposed conceptual model for the diffusion of construction innovation is based on the ten factors that were grouped under the four headings, namely the innovation attributes, industry characteristics, adopter innovative characteristics and environmental interventions as shown in Fig. 1. The proposed conceptual model followed mainly the framework on the adopter behavior developed by Brown (1981), with minor changes. Thus, environmental interventions were similar in meaning to the institutional effects (Brown, 1981), but the innovative characteristics of adopting firms were focused here instead of firm characteristics.
While, the concept of innovation attributes was adopted from Rogers (1995).

Consistent with the study main objective, the conceptual model focused on the extent of diffusion as the dependent variable. Essentially, it was theorized that the interaction among factors of innovation attributes, industry characteristics and adopter innovative characteristics initiated the diffusion process. The extent of diffusion was caused by the forces of technology push and demand pull created by the interaction. Moderating factors of environmental interventions were theorized to influence the diffusion process much later, resulting in significant changes.

Basing on the conceptual model, the first hypotheses of this study was formalized as follows:

H1: The ten factors grouped under the four headings namely innovation attributes, industry characteristics, adopter innovative characteristics and environmental interventions will significantly explain the variance in the extent of innovation diffusion.

The other hypotheses formalized from literature review are listed below: 
H2: Relative advantage of an innovation is positively related to the diffusion of innovation.

H3: Complexity of an innovation is negatively related to the diffusion of innovation.

H4: High social responsibility associated with construction product is negatively related to the diffusion of innovation.

H5: Cyclical market of construction industry is negatively related to the diffusion of innovation.

H6: Traditional procurement practice in construction industry is negatively related to the diffusion of innovation.

H7: Innovative culture in construction firms is positively related to the diffusion of

H8: Innovation champion in construction firm is positively related to the diffusion of innovation.

H9: Clients' involvement is positively related to the diffusion of innovation.

H10: Regulatory control in construction industry is positively related to the diffusion of innovation

\section{MATERIALS AND METHODS}

Construction technological innovations consist of two types namely innovation in construction processes and innovation in finished product or its components. This study narrowed down its scope on the home-grown technological innovations. The construction firms were focused in this study because they are often the end-users of these innovations. The sample was limited to large construction firms (classified by CIDB (2005a) as Class G7 which is defines as firm with unlimited tendering capacity of above RM 10 million, which were most likely to have adopted home-grown technological innovations.

\subsection{Questionnaire Survey}

The method of collecting primary data was by selfadministered mail survey. Systematic sampling method was used and sampling size of 340 was obtained using Cochran's formula. However, to allow for nondeliverable and non-responded members, the sample size was increased to 527, which was 1.55 times more.

The survey instrument was designed to model after Cavell et al. (2004), but with modification to capture data for the validation of conceptual model. Close-ended questions were used to measure the data mainly on interval and ordinal scales to facilitate data analysis using the computer software called Statistical Package for Social Science (SPSS) Version 12. The survey questionnaire was pre-tested on 20 professionals from the construction industry to gauge its comprehensiveness and clarity. Basing on the feedbacks of the pilot survey, some words were replaced and certain sentences rephrased. This was to ensure the level of language used was appropriate to the respondents in the industry and the questions were easily understood and non-ambiguous.

For rigorous and formal research, the interval and ratio measurement scales were preferred. In this study, nominal, ordinal and interval scales were used to measure the variables, but interval scale was used in majority of the questions. For this purpose, the 5-Likert scale was used consistently throughout to ensure uniformity and to facilitate the comparison of data. Sekaran (2003) says that 5-Likert scale was just as good as any, because research had indicated no significant improvement in reliability by increasing to 7 or 9 points.

To assess the reliability of data collected, a reliability test of Cronbach's alpha was carried out using the SPSS computer software. The values of Cronbach's alpha obtained for the variables were well above the required 0.7 , indicating acceptable reliability. The questionnaire was considered adequate and ready for the mail survey exercise.

\section{RESULTS}

Results of data analysis are presented as descriptive statistics, inferential statistics and hypotheses testing. The descriptive statistics provide "a feel for data" (Sekaran, 2003), which include frequency distribution, mean and standard deviation. The inferential statistics indicate the "goodness of data" (Sekaran, 2003), which include Cronbach's coefficient of alpha for reliability test, factor analysis for testing validity. Pearson's correlation analysis was used to establish correlation of variables and one-way ANOVA for variance. Multiple regression and ANOVA were used to test the hypotheses.

The response rate was $28.5 \%$ and was considered satisfactory, especially if comparison was made with the $3.4 \%$ obtained by a similar survey carried out by CIDB (2003). The breakdown of respondents by job function is shown in Fig 2.

The respondents of questionnaires were senior staff in the organization, which lends credibility to the 
findings. This study on innovation required responses from senior management staff, because they are normally the persons in the organization involved in planning and strategy with regards to innovation and technology adoption. It is noted that half of the respondents were leaders in their organizations, which implied the importance they placed on the subject of the survey.

Figure 3 shows the histogram and the normal distribution curve of the respondents by number of years in business. The distribution of these firms was normal with a mean of 15.1 and standard deviation equals to 7.96. This implied that the respondents were well established in the market and should have the opportunities of being exposed to the two home-grown innovations in the survey.

Table 1 shows the values of Cronbach's alpha for the four explanatory variables, which were all above the value of 0.7. 'Industry Characteristics' and 'Adopter Innovative Characteristics' were between the category of respectable, while the reliability of measures for the other two variables, namely Innovation Attributes and Environmental Interventions were regarded as very good. Thus, the internal consistency reliability of the measures used in this study could be considered as good.

A total of 40 items were designed in the questionnaires to capture data for the four explanatory variables, namely Innovation Attributes, Industry Characteristics, Adopter Innovative Characteristics and Environmental Interventions. These 40 items were factor analyzed, using Varimax as the rotation method and principal axis factoring as the extraction method. The Kaiser-Meyer-Olkin (KMO) Measure of Sampling Adequacy was 0.687 , which was greater than 0.6 (Coakes and Steed, 2003) and the Bartlett test of sphericity was significant. The results are shown in Table 2. Further, the anti-image correlation matrix revealed that measures of sampling adequacy were all above the acceptable level of 0.5. All these values indicated that the matrix was suitable for factoring.

The codes used in data analysis as shown in Table $\mathbf{3}$ are described below.

\subsection{High Social Responsibility}

- HSR1-safety during construction

- HSR2-minimum disturbance to public during construction

- HSR3-finished product is of quality

- HSR4-comfort and safety of end users
- HSR5-protection of environment

\subsection{Environmental Interventions}

- EI1-public complaints

- EI2-building codes

- EI3-regulations and rules

- EI4-client's specific instruction

- EI5-incentives from client

- EI6-pressure from non-government organizations (NGOs)

\subsection{Relative Advantages}

- INVIMP1-increase profitability

- INVIMP2-save labor

- INVIMP3-save material and reduce wastage

- INVIMP4-shorter construction time

- INVIMP5-better quality control

- INVIMP6-improve safety at site

- INVIMP7-cleaner site and working environment

- INVIMP8-promote better company image

\subsection{Complexity}

- INVATT1-easy to understand and use

- INVATT2-no extra manpower

- INVATT3-no extra training

- INVATT4-no extra cost

- INVATT5-no new staff with special skills

- INVATT6-no change to familiar construction processes

\subsection{Traditional Procurement Practice}

- PP1-jobs awarded to the lowest bids

- PP2-separation of design and build

- PP3-lack of partnering concept

- PP4-unfriendly relationship in project team

- PP5-multi-layered subcontracting

Table 1. Cronbach's coefficient alpha of variables

\begin{tabular}{lll}
\hline $\begin{array}{l}\text { Explanatory variables } \\
\text { Alpha }\end{array}$ & No. of items & Chronbach's \\
\hline Innovation Attributes & 14 & 0.857 \\
Industry Characteristics & 15 & 0.772 \\
Adopter Innovative Characteristics & 5 & 0.774 \\
Environmental Interventions & 6 & 0.821 \\
\hline
\end{tabular}


Ahmad Rahman Songip et al. / American Journal of Applied Sciences, 10 (2): 147-158, 2013

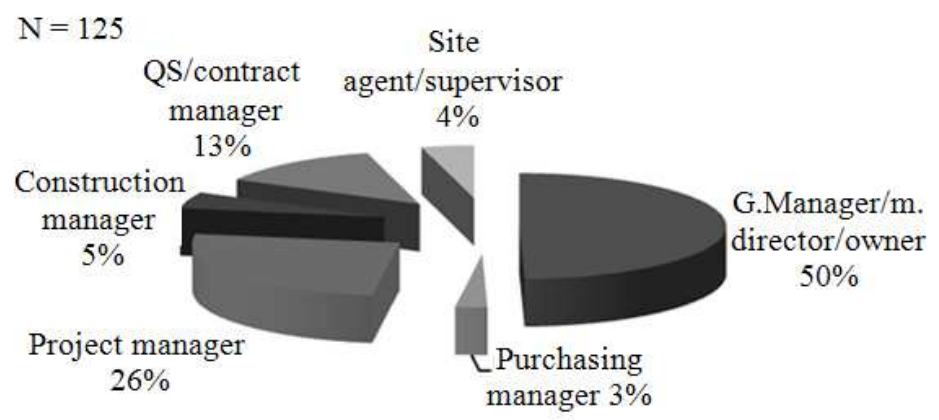

Fig. 2. Breakdown of respondents by job function



Fig. 3. Construction firms by number of years in business

Table 2. KMO and Bartlett's test

Kaiser-Meyer-Olkin measure of sampling adequacy

Bartlett's Test of Sphericity

Approx. chi-square

df

significance 
Table 3. Rotated factor matrix

\begin{tabular}{|c|c|c|c|c|c|c|c|c|}
\hline & 1 & 2 & 3 & 4 & 5 & 6 & 7 & 8 \\
\hline HSR5 & 0.839 & & 0.132 & & & & & 0.197 \\
\hline HSR4 & 0.725 & & & -0.101 & 0.115 & -0.115 & 0.160 & \\
\hline HSR2 & 0.664 & 0.112 & 0.192 & & & -0.113 & & \\
\hline HSR3 & 0.635 & & 0.254 & & & -0.171 & 0.220 & \\
\hline HSR1 & 0.609 & -0.102 & 0.245 & & & 0.133 & & \\
\hline INVATT1 & 0.404 & & 0.143 & 0.334 & 0.137 & & 0.277 & 0.304 \\
\hline EI3 & -0.233 & 0.811 & 0.147 & & & -0.118 & -0.167 & \\
\hline EI5 & & 0.733 & & & & & & \\
\hline EI2 & & 0.718 & & & & & -0.141 & \\
\hline EI6 & 0.120 & 0.638 & & & & & 0.220 & \\
\hline EI4 & & 0.637 & & & & & & -0.168 \\
\hline EI1 & & 0.601 & & & & 0.109 & 0.104 & 0.119 \\
\hline INVIMP6 & 0.225 & & 0.809 & & & & 0.219 & \\
\hline INVIMP5 & 0.252 & 0.104 & 0.687 & & 0.118 & & 0.222 & \\
\hline INVIMP7 & 0.383 & & 0.659 & & & & 0.190 & \\
\hline INVIMP4 & & & 0.654 & & & & 0.279 & 0.140 \\
\hline INVIMP8 & 0.419 & & 0.562 & & & -0.109 & & \\
\hline PP3 & & & & 0.684 & & 0.159 & & 0.109 \\
\hline PP5 & & & 0.125 & 0.663 & & 0.159 & & 0.106 \\
\hline PP2 & & & & 0.629 & 0.253 & & & \\
\hline PP4 & 0.156 & & & 0.614 & & 0.190 & -0.141 & 0.279 \\
\hline PP1 & & & & 0.456 & 0.277 & & 0.107 & \\
\hline CCF5 & -0.257 & & & 0.424 & 0.128 & 0.375 & 0.164 & \\
\hline CM5 & 0.127 & & 0.112 & 0.176 & 0.692 & & & 0.147 \\
\hline CM1 & & & & & 0.673 & & & 0.150 \\
\hline CM2 & & 0.127 & & 0.140 & 0.648 & & 0.244 & \\
\hline CM3 & & & -0.181 & & 0.500 & & & 0.353 \\
\hline CM4 & & 0.108 & 0.279 & 0.244 & 0.470 & & -0.124 & \\
\hline CCF2 & & & & & & 0.809 & & \\
\hline CCF3 & & & & 0.108 & & 0.773 & -0.165 & \\
\hline CCF1 & & & & 0.303 & & 0.601 & & \\
\hline CCF4 & & -0.173 & -0.107 & 0.425 & & 0.461 & 0.163 & \\
\hline INVIMP2 & & & 0.281 & 0.126 & 0.101 & -0.116 & 0.691 & 0.254 \\
\hline INVIMP3 & 0.159 & & 0.248 & & & & 0.690 & \\
\hline INVATT2 & 0.202 & & 0.137 & 0.265 & & & 0.452 & 0.407 \\
\hline INVIMP1 & & & 0.198 & & 0.297 & & 0.450 & 0.100 \\
\hline INVATT3 & & & 0.219 & & 0.225 & -0.158 & & 0.753 \\
\hline INVATT6 & 0.121 & & & 0.127 & 0.308 & & 0.179 & 0.604 \\
\hline INVATT5 & 0.281 & & & 0.213 & 0.124 & -0.241 & 0.299 & 0.551 \\
\hline INVATT4 & & & & & 0.170 & & 0.288 & 0.382 \\
\hline
\end{tabular}

Table 4. Model summary of multiple regression analysis

\begin{tabular}{lllll}
\hline Model & $\mathrm{R}$ & $\mathrm{R}$ Square & Adjusted R Square & Std. Error of the Estimate \\
\hline 1 & $0.548(\mathrm{a})$ & 0.300 & 0.219 & 1.48490
\end{tabular}

(a) Predictors: (Constant), public pressure, innovation champion, cyclical market, high social responsibility, traditional procurement practice, clients' involvement, relative advantage, complexity, regulatory control, innovation culture

Table 5. ANOVA analysis

\begin{tabular}{llllll}
\hline Model & Sum of Squares & df & Mean Square & F & Sig. \\
\hline 1 Regression & 81.387 & 10 & 8.139 & 3.691 & $0.000(\mathrm{a})$ \\
Residual & 189.623 & 86 & 2.205 & & \\
Total & 271.010 & 96 & & & \\
\hline
\end{tabular}

(a) Predictors: (Constant), public pressure, innovation champion, cyclical market, high social responsibility, traditional procurement practice, clients' involvement, relative advantage, complexity, regulatory control, innovation culture 


\subsection{Cyclical Market}

- CC1-uncertainties in market outlook

- $\quad$ CC2-high risks

- $\quad$ CC3-strong competition and price cutting

- CC4-need to venture overseas for growth

- CC5-difficulties of attracting and retaining young professionals

\subsection{Characteristics of Construction Firms}

- CCF1-short-term profit without a business vision

- CCF2-no innovative culture

- CCF3-no innovation champion

- CCF4-lack of surplus resources for research and development

- CCF5-depend on cheap and untrained foreign workers

From factor matrix in Table 3, eight factors with eigenvalue greater than 1.0 were extracted, which cumulatively explained $54.8 \%$ of the total variance as follows:

- Factor 1 comprised five items measuring the concept of 'High Social Responsibilities' with loading ranging from 0.609 to 0.839

- Factor 2 comprised six items measuring the concept of 'Environmental Interventions' with loading ranging from 0.601 to 0.811

- Factor 3 comprised five items measuring the concept of 'Innovation Attributes' relating to improvement aspects (INVIMP) with loading ranging from 0.562 to 0.809

- Factor 4 comprised five items measuring the concept of 'Procurement Practice' with loading ranging from 0.456 to 0.684

- Factor 5 comprised five items measuring the concept of 'Cyclical Market' with loading ranging from 0.47 to 0.692

- Factor 6 comprised four items measuring the concept of 'Characteristics of construction firm' with loading ranging from 0.461 to 0.809

- Factor 7 and 8 comprised a total of eight items measuring 'Innovation Attributes' with loading ranging from 0.382 to 0.753

"Innovation Attributes", were extracted into three factors, which indicated the different aspects of the concept. With the exception of one or two items (e.g. IVATT1 and CCF5), the items yielded eighth factors with the right variable loading on each factor. In other words, the items measured the concept correctly, thus the construct validity was good.

\subsection{Hypotheses Testing}

Eleven hypotheses were developed. The ten factors that were hypothesized to influence the extent of diffusion are, namely relative advantages, complexity, high social responsibility, cyclical market, traditional procurement practice, innovative culture, innovation champion, clients' involvement, regulatory control and public pressure. These hypotheses were tested using ANOVA to explain variance and multiple regressions to establish their relationship to the diffusion process.

The testing of hypothesis was by ANOVA analysis which was done in conjunction with multiple regression analysis that established the direction of relationship of various factors with the extent of diffusion. The results are presented as follows.

From Table 4, the $\mathrm{R}$ square value was 0.300 indicating that the ten factors jointly explained thirty percent of the variance in the extent of diffusion. This percentage might seem low, but was considered normal for data collected by survey method due to its lower accuracy in measurement (Veaux et al., 2005). The ANOVA analysis shown in Table $\mathbf{5}$ indicated an $\mathrm{F}$ value of 3.691 at highly significant level $(p<0.05)$. Therefore, the first hypothesis (H1) was accepted, i.e., the ten factors significantly explained the variance in the extent of innovation diffusion.

From Table 6, the relationship of factors with the extent of diffusion could be expressed as follows:

Extent of diffusion $=1.065+0.038($ RELADV $)-$ $0.153($ COMPLEX) +

$$
0.102 \text { (HISORES) - 0.072(CYCLICM) - }
$$

0.057 (PROCURE) $+0.438($ INNCULT $)+$

$0.055($ INNCHAM $)+0.2$ (CLIENT) + 0.115(REGULAT) - 0.093(PUBLIC)

From Table 7, hypotheses H2, H3, H5, H6, H7, H8, $\mathrm{H} 9$ and $\mathrm{H} 10$ were supported, whereas hypotheses $\mathrm{H} 4$ and H11 were not supported. In other words, while relative advantages and complexity of innovation, cyclical market and traditional procurement practice of construction industry, innovative culture and innovation champion of adopter and clients' involvement and regulatory control influenced the diffusion of innovation in the manner hypothesized, whereas high social responsibility of the industry and public pressure did not influence diffusion of innovation in the manner hypothesized. 
Table 6. Coefficients of factors

\begin{tabular}{|c|c|c|c|c|c|}
\hline \multirow[b]{2}{*}{ Model } & \multicolumn{2}{|c|}{ Unstandardized Coefficients } & \multirow{2}{*}{$\begin{array}{l}\text { Standardized } \\
\text { Coefficients } \\
\text { Beta }\end{array}$} & \multirow[b]{2}{*}{$\mathrm{t}$} & \multirow[b]{2}{*}{ Sig. } \\
\hline & B & Std. Error & & & \\
\hline 1 (Constant) & 1.065 & 2.740 & & 0.389 & 0.699 \\
\hline Relative advantage & 0.018 & 0.051 & 0.038 & 0.347 & 0.729 \\
\hline Complexity & -0.078 & 0.058 & -0.153 & -1.357 & 0.178 \\
\hline Cyclical market & -0.045 & 0.062 & -0.072 & -0.724 & 0.471 \\
\hline High social responsibility & 0.074 & 0.078 & 0.102 & 0.959 & 0.340 \\
\hline Traditional procurement practice & -0.033 & 0.061 & -0.057 & -0.548 & 0.585 \\
\hline Innovation culture & 0.275 & 0.078 & 0.438 & 3.515 & 0.001 \\
\hline Innovation champion & 0.106 & 0.230 & 0.055 & 0.461 & 0.646 \\
\hline Clients' involvement & 0.182 & 0.108 & 0.200 & 1.690 & 0.095 \\
\hline Regulatory control & 0.105 & 0.110 & 0.115 & 0.954 & 0.343 \\
\hline Public pressure & -0.118 & 0.138 & -0.093 & -0.854 & 0.396 \\
\hline
\end{tabular}

Table 7. Hypothesis and results of hypothesis testing

\begin{tabular}{|c|c|c|c|}
\hline Factors influencing diffusion & Code & $\begin{array}{l}\text { Hypothesized } \\
\text { effect }\end{array}$ & $\begin{array}{l}\text { Test } \\
\text { result }\end{array}$ \\
\hline \multicolumn{4}{|l|}{ Innovation Attributes } \\
\hline $\mathrm{H} 2$ : Relative advantages & RELADV & Positive & Positive \\
\hline H3: Complexity & COMPLEX & Negative & Negative \\
\hline \multicolumn{4}{|l|}{ Industry Characteristics } \\
\hline H4: High social responsibility & HISORES & Negative & Positive \\
\hline H5: Cyclical market & CYCLICM & Negative & Negative \\
\hline H6: Traditional procurement practice & PROCURE & Negative & Negative \\
\hline \multicolumn{4}{|l|}{ Adopter Innovative Characteristics } \\
\hline H7: Innovative culture & INNCULT & Positive & Positive \\
\hline H8: Innovation champion & INNCHAM & Positive & Positive \\
\hline \multicolumn{4}{|l|}{ Environmental Interventions } \\
\hline H9: Clients' involvement & CLIENT & Positive & Positive \\
\hline H10: Regulatory control & REGULAT & Positive & Positive \\
\hline H1 1: Public pressure & PUBLIC & Positive & Negative \\
\hline
\end{tabular}

\section{DISCUSSION}

Hypotheses H1 was substantiated, indicating that the ten factors influenced the diffusion of innovation. These factors were relative advantages and complexity of innovation, high social responsibility, cyclical market and traditional procurement practice associated with the construction industry, the innovative culture and innovation champion of the firms, clients' involvement, regulatory control and public pressure. Among these factors, innovative culture was the most significant $(p<0.05)$ that influenced diffusion positively. Innovative culture existing in an organization logically natures the individual innovativeness, which eventually leads to an innovative organization. Firms possessing innovative culture are more willing to try out new things; they are prepared to take risks, or uncertainty of innovations. It is logical that this type of culture would enhance adoption process, thus directly impact the diffusion of innovation.
The positive influence of innovative culture on the diffusion of innovation is supported in previous studies (Brown, 1981; Steele and Murray, 2001; Hiver et al., 2003; Ling, 2003; Autant-Bernard et al., 2010).

With the exception of hypotheses $\mathrm{H} 4$ and $\mathrm{H} 11$, the rest of the hypotheses were substantiated. For those factors with substantiated hypothesized effects on the diffusion of innovation, the rationale of selecting them was confirmed.

The two factors, namely high social responsibility and public pressure were not substantiated. Previously, it was argued that construction innovations were inherently associated with risks (i.e., negative to innovation diffusion). As construction products are associated with high social responsibility, because any failures can be harmful to the dwellers or the general public, construction innovations are deemed to be risky. Construction innovations, however, can be made to perform safely and satisfactorily if proper rules and regulation are drafted to guide their usage (Gann, 2000). 
Ahmad Rahman Songip et al. / American Journal of Applied Sciences, 10 (2): 147-158, 2013

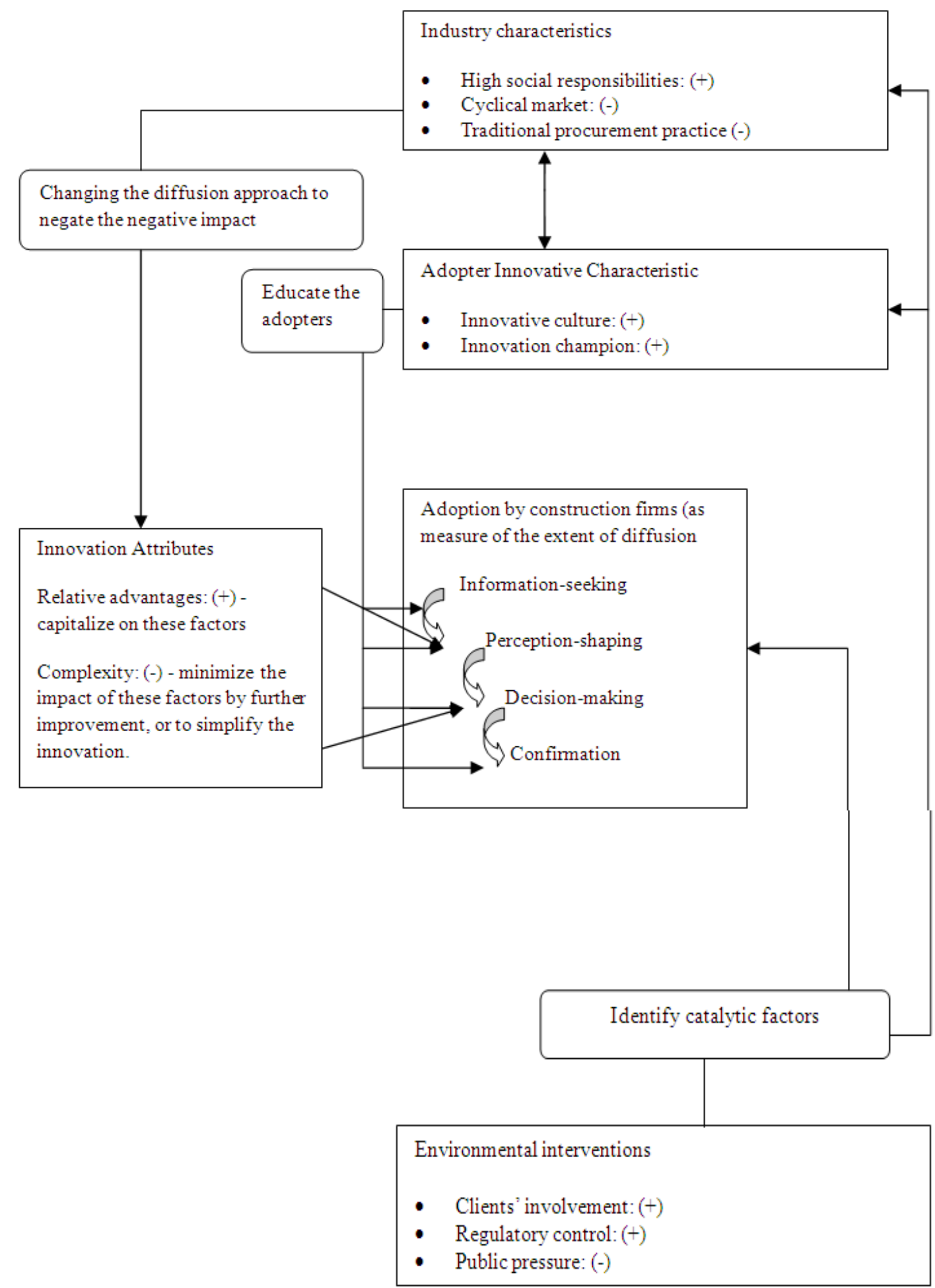

Fig. 4. Integrated model of construction innovation diffusion 
Manley et al. (2005) report that rules and regulations are drivers of innovation in Australia building industry. In US home building industry, Blackley and Shepard (1996) have reported similar finding. If this is so, established construction innovations with significant relative advantages over existing technologies will be viewed as meeting the desire of the public. It is true if these innovations can address an environmental or social problem. Thus, high social responsibility has become the driver to have proper code of practice, rules and regulation to guide the usage of construction innovations, whereby the degree of risk associated with them can be reduced to enhance their adoption.

Public pressure was found to be negatively related to the diffusion of innovation, which was opposite to what was hypothesized. It is noted that the coefficient of factor was relatively small with a value of 0.093 . Though the negative relationship differs from the hypothesized effect, the strength of relationship was small. Thus, it may not be sufficient to generalize it to all innovations, as the balance can be tilted the other way for certain innovations. As such, it can be interpreted that this factor is innovationspecific. This warrants further study to be carried out on the influence of this factor in the case of other construction innovations in order to gain better insights.

An integrated model of construction innovation diffusion was developed from the conceptual model by incorporating the results and findings of this study as depicted in Fig 4. It provides guidance to innovation developers in better understanding of the diffusion process, thus leading to improved adoption of their construction innovations. Incorporating the adoption decision-making stages by Rogers (1995), it shows the impact of the interaction of these factors in determining the extent of diffusion of an innovation.

\section{CONCLUSION}

An empirical study was conducted to meet the objective of investigating the factors that influence the diffusion of construction innovations. An integrated model to guide future diffusion of construction innovations was developed. It is intended to benefit the innovation developers in improving the adoption rate of their homegrown construction innovations. This study will benefit other developing countries which share similar settings with Malaysia. Future research can focus on a longitudinal study with the same theme and scope to follow through the diffusion process.

\section{REFERENCES}

Autant-Bernard, C., M. Fadairo and N. Massard, 2010. Knowledge diffusion and innovation policies within the European regions: Challenges based on recent empirical evidence. Res. Policy, 42: 196-210. DOI: 10.1016/j.respol.2012.07.009

Blackley, D.M. and E.M. Shepard, 1996. The diffusion of innovation in home building. J. Hous. Econ., 5: 303-322. DOI: 10.1006/jhec.1996.0016

Brochner, J., 2011. New ouput quality indicators in construction productivity measurement. Proceedings of the Management and Innovation for a Sustainable Built Environment, Jun. 20-23, The Netherlands, Amsterdam.

Brown, L.A., 1981. Innovation Diffusion: A New Perspective. 1st Edn., Routledge, ISBN-10: 041674270X, pp: 345.

CIDB, 2003. Survey on the usage of Industrialized Building System (IBS) in Malaysia Construction Industry. Construction Industry Development Board, Malaysia.

CIDB, 2005a. Malaysian construction industry at a glance-construction in Malaysia 2003-2004: An overview. Construction Industry Development Board, Malaysia.

CIDB, 2005b. Malaysian construction industry master plan 2005-2015. Construction Industry Development Board.

Coakes, S.J. and L.G. Steed, 2003. SPSS Analysis Without Anguish. 1st Edn., John Wiley and Sons, Milton, ISBN-10: 0470802774, pp: 242.

Dieperinka, C., I. Brand and W. Vermeulen, 2004. Diffusion of energy-saving innovations in industry and the built environment: Dutch studies as inputs for a more integrated analytical framework. Energy Policy, 32: 773-784. DOI: 10.1016/S03014215(02)00341-5

Gann, D., 2000. Can regulations promote construction innovation?

Hall, B.H. and B. Khan, 2002. Adoption of new technology. University of California at Berkeley.

Hiver, W., W.E. Hopkins and S.A. Hopkins, 2003 Facilitating, accelerating and sustaining the innovation diffusion process: An epidemic modeling approach. Eur. J. Innov. Manage., 6: 80-89. DOI: $10.1108 / 14601060310475237$ 
Holt, G.D. and D.J. Edwards, 2012. Innovation or business survival?: A preliminary, qualitative study of UK construction plant supply chains. Cons. Innov.: Inform., Process, Manage., 12: 99-122. DOI: $10.1108 / 14714171211197526$

Hussain, M.F. and S. Ilyas, 2011. Environment for innovation: Gaining competitive advantage. Afr. J. Bus. Manage., 5: 1232-1235. DOI: 10.5897/AJBM10.597

Kale, S. and D. Arditi, 2010. Innovation diffusion modeling in the construction industry. J. Const. Eng. Manage., 136: 329-340. DOI: 10.1061/(ASCE)CO.1943-7862.0000134

Cavell, M., E. Hudson, T.C. Koebel and M. Papadakis, 2004. The diffusion of innovation in the residential building industry. Department of Housing and Urban Development.

Ling, F.Y.Y., 2003. Managing the implementation of construction innovations. Const. Manage. Econ., 21: 635-649. DOI: 10.1080/0144619032000123725

Larsen, G.D., 2005. Horses for courses: Relating innovation diffusion concepts to the stages of the diffusion process. Const. Manage. Econ., 23: 787-792. DOI: $10.1080 / 01446190500204770$

Larsen, G.D. and T.M.A. Ballal, 2005. The diffusion of innovations within a UKCI context: An explanatory framework. Const. Manage. Econ., 23: 81-91. DOI: 10.1080/0144619042000287750

Manley, K., M.A. Blayse and M. Swainston, 2005. Implementing innovation on commercial building projects in Australia. Proceedings of the Clients Driving Innovation International Conference, Oct. 25-27, Gold Coast, Australia.

Materna, A.T., 1981. Study of management factors affecting innovation diffusion of high technology. Ph.D. Thesis, Claremont Graduate School.
Murray, C.E., 2009. Diffusion of innovation theory: A bridge for the research-practice gap in counseling. J. Counsel. Dev., 87: 108-116. DOI: 10.1002/j.15566678.2009.tb00556.x

Panuwatwanich, K., R.A. Stewart and S. Mohamed, 2009. Critical pathways to enhanced innovation diffusion and business performance in Australian design firms. Automat. Const., 18: 790-797. DOI: 10.1016/j.autcon.2009.03.001

Rogers, E.M., U.E. Medina, M.A. Rivera and C.J. Wiley, 2005. Complex adaptive systems and the diffusion of innovations. Innov. J., 10: 1-26.

Rogers, E.M., 1995. Diffusion of Innovations. 4th Edn., Free Press, New York, ISBN-10: 0028740742, pp: 519.

Sekaran, U., 2003. Research Methods for Business: A Skill Building Approach. 4th Edn., John Wiley and Sons, New York, ISBN-10: 0471384488, pp: 450.

Songip, A.R., B.H. Lau, K. Jusoff and H.N. Ramli, 2013. Development of a conceptual model for the diffusion of construction innovation. Aust. J. Basic Applied Sci., 7: 573-581.

Steele, J. and M. Murray, 2001. The application of structured exploration to develop a culture of innovation. Chartered Institute of Building Services Engineers.

Toole, T.M., 1998. Uncertainty and home builders' adoption of technological innovations. J. Const. Eng. Manage., 124. DOI: 10.1061/(ASCE)07339364(1998)124:4(323)

Veaux, R.D.D., P.F. Vellemen and D.E. Bock, 2005. Stats: Data and Models. 1st Edn., Pearson/Addison Wesley, Boston, ISBN-10: 0321200543, pp: 808. 